Conference paper to be submitted to The American Nuclear Society Third Topical Meeting DOE Spent Nuclear Fuel and Fissile Materials Management, September 8-11, 1998, Charleston, South Carolina.

FCF Metallic Waste Data Uncertainty Analysis

\author{
A. M. Yacout \\ Argonne National Laboratory \\ Reactor Analysis Division \\ Argonne, IL 60439
}

R. S. Herbst, T. Battisti, R. D. Mariani

Argonne National Laboratory - West

Technology Division

Idaho Falls, ID 83403

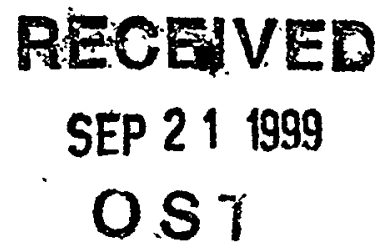

*Work supported by the U.S. Department of Energy, Nuclear Energy Programs under Contract W-31-109-ENG-38. 


\section{DISCLAIMER}

This report was prepared as an account of work sponsored by an agency of the United States Government. Neither the United States Government nor any agency thereof, nor any of their employees, make any warranty, express or implied, or assumes any legal liability or responsibility for the accuracy, completeness, or usefulness of any information, apparatus, product, or process disclosed, or represents that its use would not infringe privately owned rights. Reference herein to any specific commercial product, process, or service by trade name, trademark, manufacturer, or otherwise does not necessarily constitute or imply its endorsement, recommendation, or favoring by the United States Government or any agency thereof. The views and opinions of authors expressed herein do not necessarily state or reflect those of the United States Government or any agency thereof. 


\section{DISCLAIMER}

Portions of this document may be illegible in electronic image products. Images are produced from the best available original document. 


\title{
X. In Situ Imaging of Charge Carriers in an Electrochemical Cell
}

\author{
Rex E. Gerald II, Robert J. Klingler, Jerome W. Rathke, and Giselle Sandí

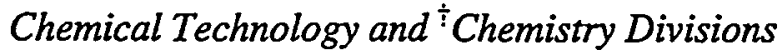 \\ Argonne National Laboratory, 9700 South Cass Avenue, Argonne, Illinois 60439 \\ Klaus Woelk \\ Institut für Physikalische und Theoretische Chemie \\ Universitât Bonn, Wegelerstr. 12, D-53115 Bonn, Germany \\ Gerald@cmt.anl.gov (630)252-4214
}

\begin{abstract}
A toroid cavity nuclear magnetic resonance (NMR) detector capable of quantitatively recording radial concentration profiles, diffusion constants, displacements of charge carriers, and radial profiles of spin-lattice relaxation time constants was employed to investigate the charge/discharge cycle of a solid-state electrochemical cell. Onedimensional radial concentration profiles (1D-images) of ions solvated in a polyethylene oxide matrix were recorded by ${ }^{19} \mathrm{~F}$ and ${ }^{7} \mathrm{Li} N \mathrm{NMR}$ for several cells. A sequence of ${ }^{19} \mathrm{~F}$ NMR images, recorded at different stages of cell polarization, revealed the evolution of a region of the polymer depleted of charge carriers. From these images it is possible to .extract the transference number for the $\mathrm{Li}^{+}$ion. Spatially localized diffusion coefficients and spin-lattice relaxation time constants can be measured simultaneously for the ions in the polymer electrolyte by a spin-labeling method that employs the radial $\mathrm{B}_{1}$-field gradient of the toroid cavity. A spatial resolution of $7 \mu \mathrm{m}$ near the working electrode was achieved with a gradient strength of 800 gauss $/ \mathrm{cm}$. With this apparatus, it is also possible to investigate novel intercalation anode materials for lithium ion storage. These materials are coated onto the working electrode in a thin film. The penetration depth of lithium cations in these films can be imaged at different times in the charge/discharge cycle of the battery.
\end{abstract}




\section{X.1 Introduction}

\section{Other Nuclei or Gas Imaging}

The demand for solid state energy storage devices that are transportable has encouraged research on solid polymer electrolytes. At room temperature, however, polymer electrolytes are currently incapable of achieving the conductivity requirements for batteries with high current output [1]. The ideal electrolyte would have the physical and mechanical properties of solids, the high conductivity characteristic of fluids, and the ability to transfer the electroactive ion exclusively [2]. Traditional NMR spectroscopy methods have been used to study ionic mobility in bulk polymer electrolytes [3]. The application of NMR imaging methods, however, can provide details of the temporal and spatial transport of charge carriers in typical polymer electrolyte systems. In particular, by combining an electrochemical cell with a toroid cavity NMR detector probe [4], it is possible to measure the macroscopic transport properties, local dynamics, and chemistry of ions as functions of distance from the electrodes.

\section{X.2 Materials and Experimental Apparatus}

The chemicals used in this work were obtained from Aldrich Chemical Co. and were used without further purification. The polyethylene oxide and lithium triflate were dissolved in hot tetrahydrofuran, which was subsequently removed by heating under vacuum. A white solid monolith remained after complete removal of the solvent. The white solid was heated for several minutes at $174^{\circ} \mathrm{C}$ in a closed container until the solid melted into a moderately viscous, clear liquid that could be handled easily. The plasticized polymer electrolyte was prepared by mixing the hot liquid polyethylene oxide polymer electrolyte with tetraglyme, propylene carbonate, and additional lithium triflate salt. The mole ratio of the electrolyte used in this work was $1.000 \mathrm{LiCF}_{3} \mathrm{SO}_{3}$ : $0.043 \mathrm{CH}_{3}\left(\mathrm{OCH}_{2} \mathrm{CH}_{2}\right)_{91} \mathrm{OCH}_{3}: 0.840 \mathrm{CH}_{3}\left(\mathrm{OCH}_{2} \mathrm{CH}_{2}\right)_{4} \mathrm{OCH}_{3}: 1.682$ propylene carbonate.

A quantity of 1.255 grams of the polymer electrolyte mixture was placed in the electrochemical cell that forms part of the toroid cavity NMR detector. The cylindrical cell was formed by a glass tube with an inside diameter of $10.4 \mathrm{~mm}$ and a length $19.6 \mathrm{~mm}$. Circular rubber septa of diameter $11 \mathrm{~mm}$ and thickness $3 \mathrm{~mm}$ (Varian Instruments, Palo Alto, California) were used to seal the tube at both ends. A $0.80 \mathrm{~mm}$ diameter gold wire counterelectrode was formed into a 5-tum helix and placed against the inner wall of the glass tube. One end protruded through the top septum. A 0.62-mm diameter copper wire (22 gauge QT, Phoenix Wire, Inc. South Hero, Vermont) passed through the center axis of the cell, piercing both septa. A potential was applied across 
the cell, with the negative and positive terminals of a potentiostat (Model EG\&G 273A) connected to the centril working electrode and the outer counterelectrode, respectively. The working electrode of the electrochemical cell assembly also functioned as the central conductor of the toroid cavity NMR probe.

Fluorine-19 NMR rotating frame images were recorded at room temperature by using a Varian LNTTY INOVA-300WB spectrometer at the following settings: spectrometer frequency, $282.224 \mathrm{MHz}$; spectral width, $6 \mathrm{kHz} ; 1024$ data points; 4-s recycle delay; four transients per spectrum; 128 spectra were recorded with a pulse width increment of $4 \mu \mathrm{s}$ (spectral width, $125 \mathrm{kHz}$ ). The two-dimensional data sets were processed with $50-\mathrm{Hz}$ and $2000-\mathrm{Hz}$ line broadening in the $\mathrm{F} 2$ and $\mathrm{F} 1$ dimensions, respectively. One-dimensional $T_{1}$ spatial images, which record the spin-lattice relaxation as a function of radial position, required that a composite $180^{\circ}$ pulse be executed prior to the acquisition of the normal rotating frame image [5].

\section{X.3 Results and Discussion}

The current vs. time profile of an electrochemical cell subjected to an applied potential is determined by the cell geometry, the equivalents of charge carried by the charge carriers, and the mobility of the charge carriers. Electrochemical cell polarization is the deleterious result of the transport of nonelectroactive ions of opposite charge. In a polarized cell, the charge carriers near one of the electrodes (the working electrode) are depleted to zero, thereby effectively forming an open circuit. In such a case, the cell ceases to function until the charge carriers near the working electrode are replenished by diffusion or other means of mass transport.

The conduction of charge through solid polymer electrolytes in an electrochemical cell can proceed very slowly, requiring an extended period of time to obtain sufficient cell polarization (i.e., decrease in total number of ions near the electrode) for observation by NMR. Therefore, we formulated a plasticized polymer electrolyte (as described above) that exhibits substantially larger charge conduction at room temperature. However, at room temperature, the plasticized polymer electrolyte slowly transforms from a viscous liquid to a heterogeneous gel or to a homogeneous waxy solid, depending on the composition. We used this electrolyte to investigate various aspects of cell polarization, including the physical dimensions and profile of the depletion zone, as depicted in Figs. X.1 and X.2, and the molecular dynamics of the anions through measurements of spatially resolved spin-lattice relaxation time constants (Figs. X.3 and X.4). 
Other Nuclei or Gas Imaging

The conductivity of this electrolyte is sufficient to make electrochemical processes observable by NMR methods that utilize the high sensitivity near the central electrode of a toroid cavity probe. In fact, while the total number of ${ }^{19} \mathrm{~F}$ spins in the detector is substantial, $13.59 \mathrm{mmol}$, the decrease in the number of ${ }^{19} \mathrm{~F}$ spins next to the working electrode following $50 \mathrm{mC}$ of charge is only $1.55 \mu \mathrm{mol}$. This decrease (about 1 part in 9000) can be seen in the difference between the vertical regions of curves $a$ and $b$ in Fig. X.2. Of course, this miniscule change in the total number of ${ }^{19} \mathrm{~F}$ spins can be observed because it is spatially confined to a very small volume (an annular shell of radius $310 \mu \mathrm{m}$, thickness $10-20 \mu \mathrm{m}$, and height $12.9 \mathrm{~mm}$ ), where the change in the ${ }^{19} \mathrm{~F}$ spins is nearly $100 \%$.

Figure X.4 shows the spin-lattice relaxation time constants (including their respective standard errors) plotted as a function of the radial distance from the working electrode. The curve suggests that the triflate anions are not entirely depleted in the volume around the working electrode. These data were recorded for the cell in the state of polarization depicted by image $d$ of Fig. X.1. The spatial resolution near the electrode surface is $7 \mu \mathrm{m}$; therefore, the $T_{1}$ value for the region next to the working electrode is obtained from the residual ${ }^{19} \mathrm{~F}$ signal from a volume shell of radius $310 \mu \mathrm{m}$, thickness $7 \mu \mathrm{m}$, and height $12.9 \mathrm{~mm}$.

Very little is known about the effects on the polymer structure and the ion mobility by concentration gradients in the electrolyte. It is generally believed that the cations tend to crosslink the polymer chains, thereby influencing the segmental motion of the polymer $[1,6]$. Furthermore, the segmental motion is commonly believed to be the most important factor controlling the ionic conductivity in polymer electrolytes. Importantly, there are fluctuating effects in the region adjacent to the electrodes due to the dynamic nature of the concentration gradients of ions in the polymer matrix. With the toroid cavity/electrochemical cell NMR imager described here it is possible for the first time to probe for structure and mobility differences in the polymer and ions across the concentration gradients in the electrolyte by measuring the NMR spin relaxation time constants, $T_{1}, T_{l_{\rho}}$, and $T_{2}$, as a function of distance from the electrodes. Thus, the NMR imaging method described here is capable of addressing some of the most important questions with regard to the dynamics of the polymer-electrolyte performance. Does the ratio of amorphous-to-crystalline polymer phases change in the immediate vicinity of the electrodes as the concentration gradients in the electrolyte evolve? Is the segmental motion of the polymer uniform throughout the cell? How quickly do the ionic crosslinks reform as the concentration of the ions in the polymer matrix increases? On what time-scale do the ions in the amorphous and crystalline polymer-electrolyte phases undergo exchange? In addition, since the toroid cavity/electrochemical cell NMR imager records chemical shifts and coupling constants, we are able to explore various chemical 
transformations that occur during cell operation. What ancillary oxidation/reduction reactions take place at the electrodes? What side reactions do lithium ions undergo when they intercalate into the pores of carbon based materials, which serve as novel electrodes? How is the irreversible capacity of an electrochemical cell related to the chemistry of lithium ion intercalation and deposition, and electrolyte degradation? These are just a few of the questions that are significant to modern battery research and development. In this paper we have demonstrated the feasibility of several in situ NMR imaging methods that will allow us to investigate these questions.

\section{References}

1. Ratner, M.A.; Shriver, D.F. Chem. Rev. 1988, 88, 109.

2. Mellander, B.-E.; Albinsson, I. Solid State Ionics: New Developments, Ed. Chowdari, B.V.R. 1997, 97.

3. Ward, I.M.; Boden, N.; Cruickshank, J.; Leng, S.A. Electrochimica Acta, 1995, 40, 2071.

4. Woelk, K.; Rathke, J.W.; Klingler, R.J. J. Magn. Reson. A, 1994, 109, 137.

5. Woelk, K.; Rathke, J.W. J. Magn. Reson. A, 1995, 115, 106.

6. Bruce, P.G., Vincent, C. A., J. Chem. Soc. Faraday Trans., 1993, 89, 3187.

\section{Acknowledgments}

We are indebted to Dr. Christopher Johnson of the Chemical Technology Division at Argonne National Laboratory for providing materials and helpful advice. This work was performed under the auspices of the Office of Basic Energy Sciences, Division of Chemical Sciences, U.S. Department of Energy, under contract no. W-31-109-ENG-38. The U.S. Government's right to retain a nonexclusive royalty-free license in and to the copyright covering this paper, for governmental purposes, is acknowledged. 

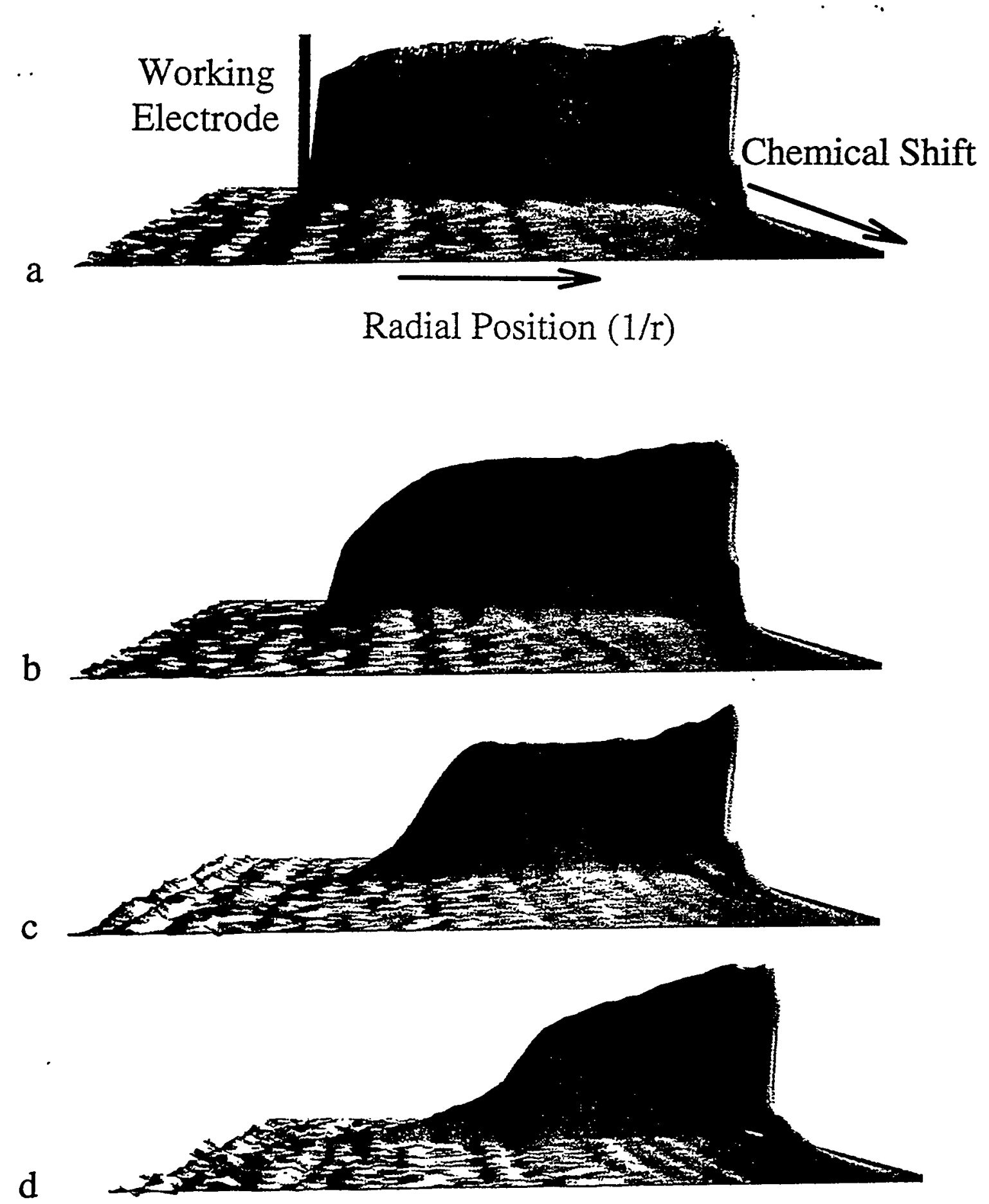

Fig. X.1: ${ }^{19} \mathrm{~F}$ NMR images of the triflate $\left(\mathrm{CF}_{3} \mathrm{SO}_{3}\right)$ anion in an amorphous polyethylene oxide based electrolyte monitoring the formation of the depletion zone during the charge half-cycle. (a) Initial profile; (b) After $50 \mathrm{mC}$; (c) After $3.5 \mathrm{~h}$ charging; (d) Following several days charging. The radial profile images are presented in reciprocal space so that the region of interest (near the working electrode) is expanded. The total number of spins decreases in the concentric annular shells closest to the working electrode, therefore, in this region the signal-to-noise ratio diminishes. 


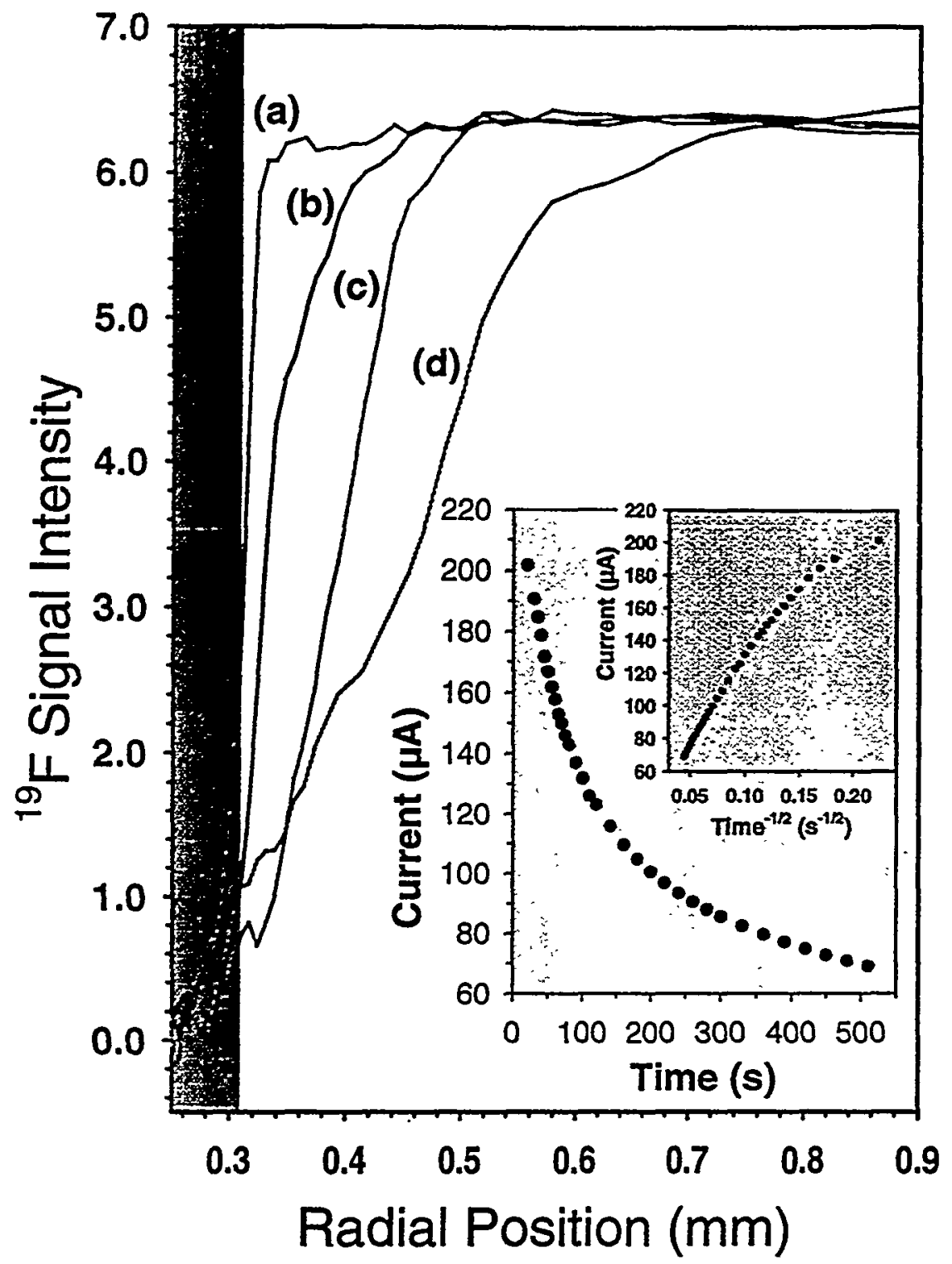

Fig. X.2: Radial profiles of the images in Fig. X.1. The gray rectangle on the left side of the figure represents the working electrode, which has a $0.31 \mathrm{~mm}$ radius. The signal intensity of each radial profile was scaled using a scale factor that was determined by averaging the measured ${ }^{19} \mathrm{~F}$ signal intensity values in the region of the electrochemical cell between 0.60 and $1.73 \mathrm{~mm}$. Across this region of the electrochemical cell all of the intensity profiles were nearly constant before and after charging the cell. The plot insets indicate a nonlinear decrease in charging current with increasing time for the time period between image profiles $a$ and $b$. We recorded the current and total accumulated charge passed through electrochemical cells of identical geometry to the cell used here to estimate the size of the depletion region at various stages of cell charging. For long charging times the current decreased linearly with the square root of charging time. and typical charging currents were 10-40 $\mu \mathrm{A}$. All the radial profiles shown here were recorded during cell charging, that is, while current was flowing through the charging circuit. No deleterious effects from the charging current on the external magnetic field homogeneity were observed under these conditions. 

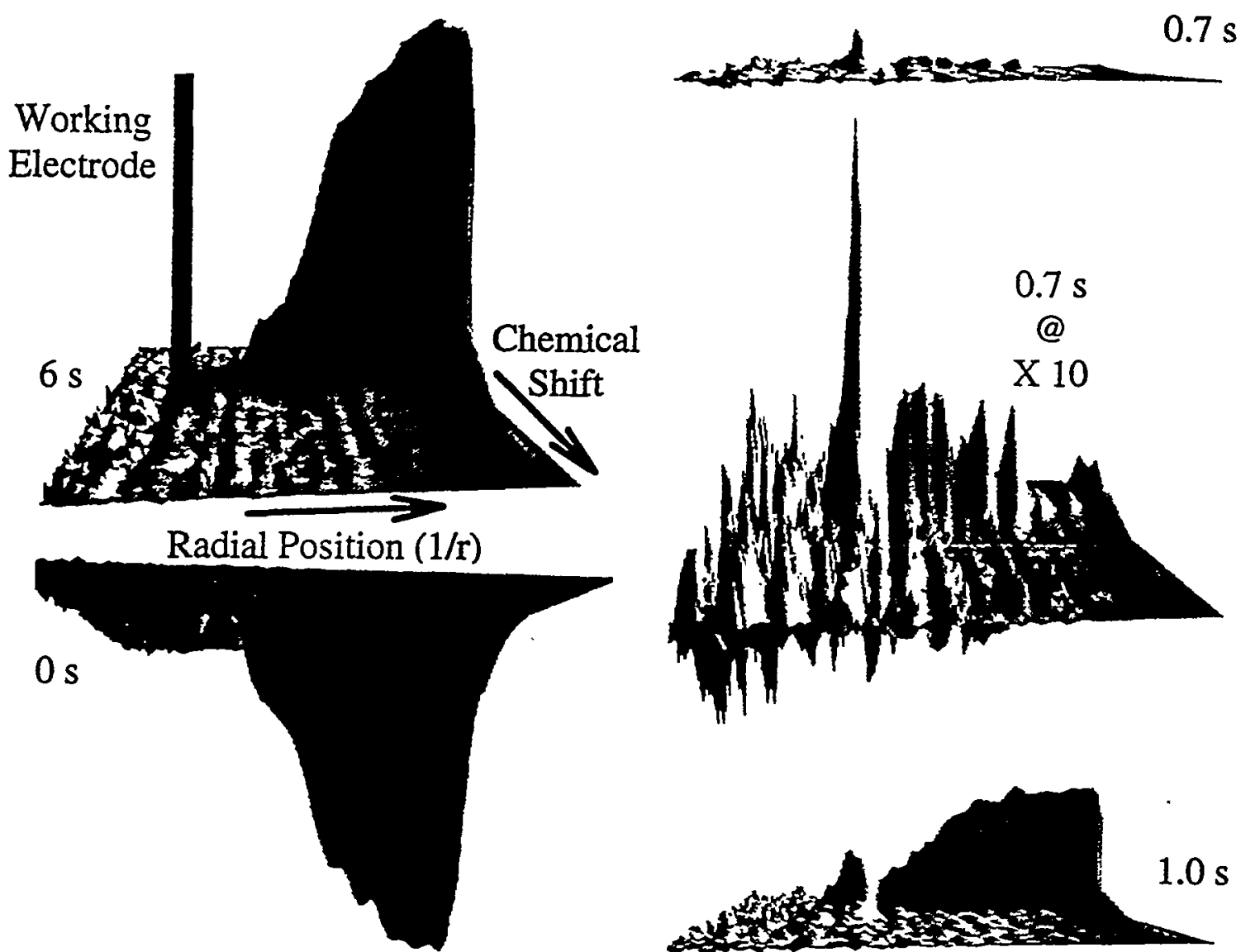

$0.2 \mathrm{~s}$

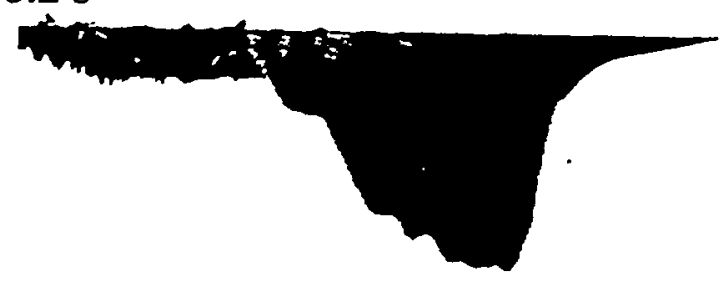

\section{$0.45 \mathrm{~s}$}
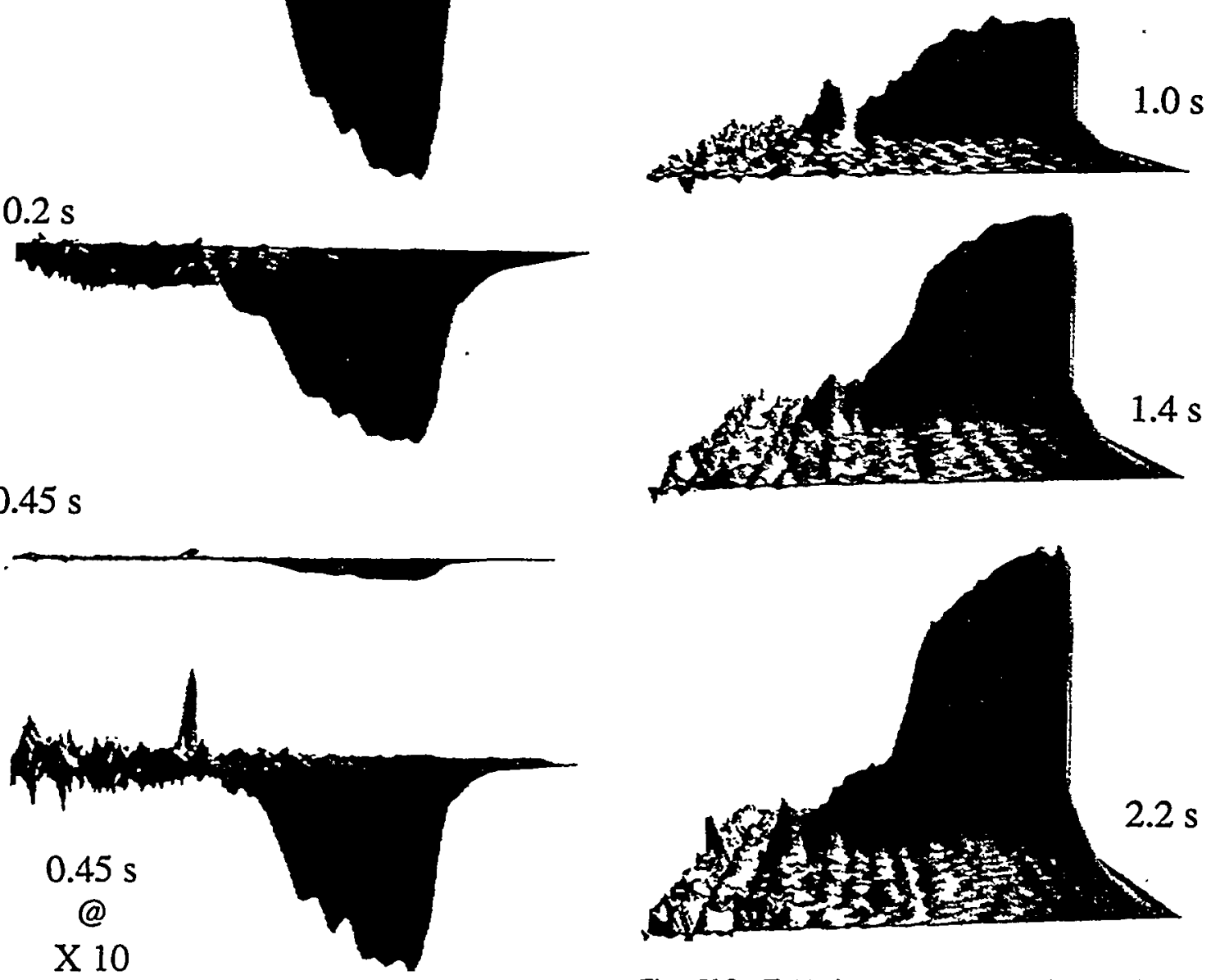

Fig. X.3: $T_{1}(r)$ images of the triflate anion across the concentration gradient of charge carriers in the plasticized polymer electrolyte. 


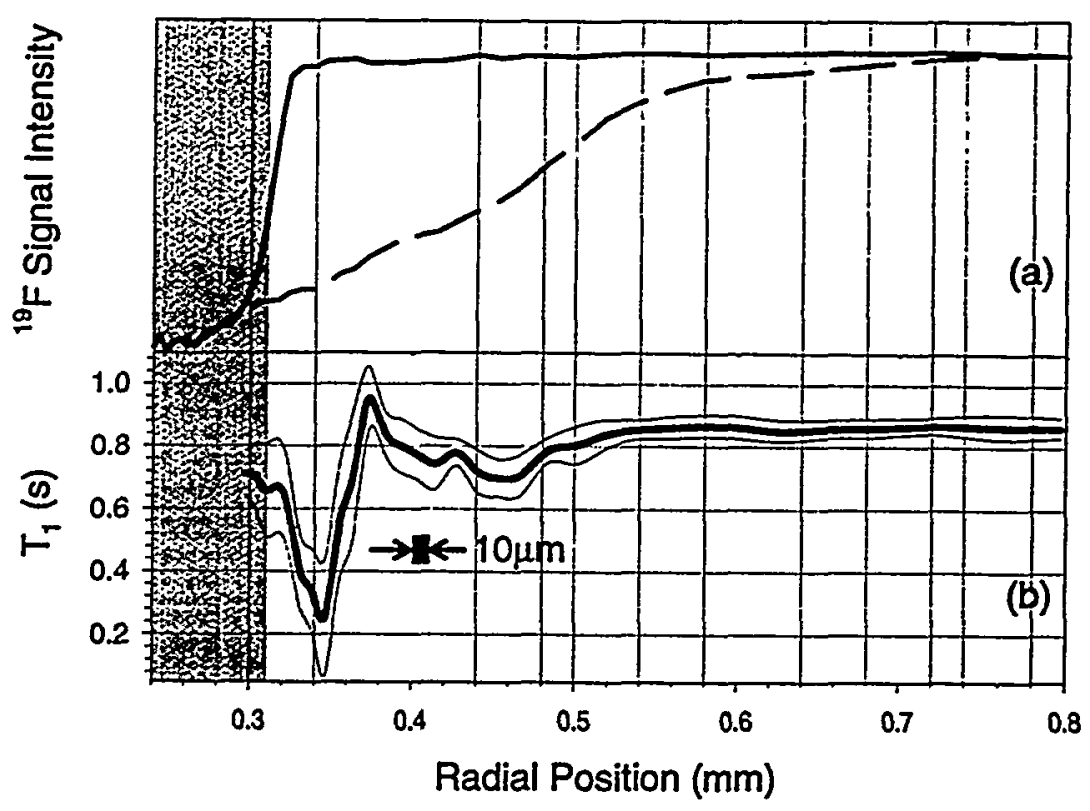

Fig. X.4: Spin-lattice relaxation time constant measurements of the ${ }^{19} \mathrm{~F}$ nuclei in the triflate anions dissolved in the plasticized polyethylene oxide electrolyte as a function of the distance from the working electrode in the polarized electrochemical cell. (a) The solid and dashed curves are the radial profiles shown as curves $a$ and $d$ in Fig. X.2, respectively. (b) The function $T_{1}(r)$ (including confidence intervals) measured for the dashed curve in (a). 